\title{
Cyanide Production and Degradation During Growth of Chromobacterium violaceum
}

\author{
By PAUL B. RODGERS AND CHRISTOPHER J. KNOWLES \\ Biological Laboratory, University of Kent, Canterbury, Kent CT2 $7 N J$
}

(Received 12 April 1978)

\begin{abstract}
Cyanogenesis by growing cultures of Chromobacterium violaceum was stimulated by the inclusion of glycine and methionine in the growth medium. Increases in the ferrous ion and phosphate concentrations of the growth medium stimulated cyanide production. Chromobacterium violaceum possesses a number of cyanide-utilizing enzymes: $\beta$-cyanoalanine synthase, $\gamma$-cyano- $\alpha$-aminobutyric acid synthase and rhodanese. Studies on the activities of these enzymes in cell-free extracts of cultures growing under both high and low cyanide-evolving conditions are presented. Addition of chloramphenicol to high and low cyanide-evolving cultures towards the end of exponential growth had a profound effect on the medium cyanide concentrations. These observations are shown to have been caused by chloramphenicol blocking the induction of the cyanide-utilizing enzymes.
\end{abstract}

\section{INTRODUCTION}

A wide range of living organisms are cyanogenic, including many eukaryotic microorganisms (Knowles, 1976). However, the only bacteria known to produce cyanide are the soil organisms Chromobacterium violaceum and a few pseudomonads. Cyanide production by $C$. violaceum and Pseudomonas aeruginosa is stimulated by addition of glycine and methionine to the medium (Michaels \& Corpe, 1965; Wissing, 1968; Castric, 1977). In the snow mould fungus, glycine stimulates cyanogenesis (Ward \& Thorn, 1966). In C. violaceum the carbon and nitrogen of cyanide are derived from the C-2 methylene group and the amino group of glycine, respectively; the carboxyl group is lost as $\mathrm{CO}_{2}$ (Michaels et al., 1965). A similar situation prevails in the snow mould fungus (Ward \& Thorn, 1966), but in $P$. aeruginosa both the $\mathrm{C}-1$ and $\mathrm{C}-2$ groups of glycine are incorporated into cyanide (Castric, 1977). The role of methionine in bacterial cyanogenesis is not known, but it possibly acts as an intermediary methyl group donor.

Cyanide-producing micro-organisms are able to assimilate or detoxify cyanide by a variety of pathways (Knowles, 1976). Chromobacterium violaceum converts cyanide to $\beta$-cyanoalanine and then aspartate, presumably as an assimilatory pathway (Brysk et al., 1969a). It also forms $\gamma$-cyano- $\alpha$-aminobutyric acid (Brysk \& Ressler, 1970) although no further metabolism appears to occur, suggesting that it is a detoxication product. As shown below, C. violaceum also forms rhodanese as a possible detoxifying agent.

It is the aim of the work presented in this paper to investigate further the conditions for cyanide production by $C$. violaceum and the relationship between the formation and utilization or degradation.

\section{METHODS}

Organism and growth conditions. Chromobacterium violaceum (NCIB 9131, D252, supplied by Dr Dorothy Jones of the University of Leicester) was grown on a minimal medium consisting of M-9 salts (Miller, 1972) with ammonium salts omitted, $1 \mathrm{ml}$ trace metals $1^{-1}$ (Bauchop \& Elsden, 1960) with the $\mathrm{Fe}^{2+}$ concentration 
raised to $30 \mu \mathrm{M}$, and $10 \mathrm{mM}$-glutamate as sole carbon and nitrogen source. Where stated, the medium was supplemented with $2 \mathrm{~mm}$-glycine and/or $0.5 \mathrm{~mm}$-methionine. A $1 \%$ (v/v) inoculum of a 20 to $24 \mathrm{~h}$ stationary phase culture grown on $10 \mathrm{~mm}$-glutamate was used to inoculate experimental flasks. In experiments where the cyanide concentration in the medium was measured growth took place in $100 \mathrm{ml}$ medium in $250 \mathrm{ml}$ conical flasks, whereas in experiments where cell-free extracts were prepared for enzyme assays growth took place in $500 \mathrm{ml}$ medium in 21 conical flasks; incubation was at $30^{\circ} \mathrm{C}$ in a rotary shaker $\left(250 \mathrm{rev}, \mathrm{min}^{-1}\right)$.

Preparation of cell-free extracts. Bacteria were centrifuged at $23000 \mathrm{~g}$ for $10 \mathrm{~min}$, washed twice with $200 \mathrm{mM}$ Tris/ $\mathrm{HCl}$ buffer $(\mathrm{pH} 8.5)$ and resuspended in $5 \mathrm{ml}$ fresh buffer. Bacteria were disrupted by sonication (MSE sonicator, $150 \mathrm{~W}, 6 \times 15 \mathrm{~s}, 0^{\circ} \mathrm{C}$ ) and centrifuged at $10000 \mathrm{~g}$ for $10 \mathrm{~min}$ at $4{ }^{\circ} \mathrm{C}$ to give a cell-free extract. Extracts were not dialysed.

Determination of enzyme activities. $\beta$-Cyanoalanine synthase was assayed by the method of Hendrickson $\&$ Conn (1969) and $\gamma$-cyano- $\alpha$-aminobutyric acid synthase was assayed by the method of Ressler et al. (1973) except that a time-course determination was used in both cases. The $\beta$-cyanoalanine synthase reaction mixture was buffered at $\mathrm{pH} 9.0$ whilst that for $\gamma$-cyano- $\alpha$-aminobutyric acid synthase was buffered at pH $9 \cdot 1$. Rhodanese was assayed as described by Smith \& Lascelles (1966).

Cyanide determination. The medium cyanide concentration in cultures of cyanogenic bacteria is a balance between the rate of cyanide synthesis by the organism, and the rate of cyanide utilization or degradation by the organism plus, since it is volatile, the rate of loss of cyanide to the environment. Preliminary experiments with cotton-wool plugged, uninoculated shake-flasks to which 150 to $250 \mu \mathrm{M}$-cyanide had been added to the growth medium showed that approx. $0.9 \mu \mathrm{mol}$ cyanide $\mathrm{h}^{-1}$ was lost; this figure was considered negligible in comparison with the rates of cyanide formation and utilization by cultures of $C$. violaceum growing under cyanogenic conditions. Castric (1975) has devised a rubber stopper for shake-flasks which has a glass tube insert containing a $\mathrm{NaOH}$ wick to trap cyanide lost from the culture. Preliminary experiments comparing the use of this type of stopper and cotton-wool plugs for cultures of $C$. violaceum confirmed that only a low level of cyanide loss occurred from the medium. Cotton-wool plugs were therefore used in all further experiments. Cyanide was assayed by the method of Epstein (1947).

Other assays. Protein was assayed by the modified biuret method of Gornall et al. (1949). Bacterial growth was measured by the absorbance at $750 \mathrm{~nm}$ using $10 \mathrm{~mm}$ cuvettes in a Pye Unicam SP500 spectrophotometer.

Chloramphenicol. Chloramphenicol was dissolved in water to a concentration of $250 \mu \mathrm{g} \mathrm{ml}^{-1}$ and filtersterilized using $0.45 \mu \mathrm{m}$ Millipore filters.

Chemicals. Chloramphenicol was obtained from Sigma. Whenever possible, all other reagents were of analytical grade; glass-distilled water was used throughout.

\section{RESULTS}

Figure 1 shows cyanide production by $C$. violaceum grown on $10 \mathrm{~mm}$-glutamate as a combined carbon and nitrogen source, in the absence and presence of 2 mM-glycine and $0.5 \mathrm{~mm}$-methionine. For clarity, only the growth curve for glutamate alone is shown. Inclusion of glycine and/or methionine in the medium had little effect on the growth rate, although occasionally some reduction in final yield has been observed (cf. Fig. 3). The bacterium was unable to grow on glycine and/or methionine as carbon and nitrogen sources. In confirmation of the data of Michaels \& Corpe (1965), little cyanide was produced during growth on glutamate alone. Singly, glycine and methionine had little effect on cyanide production by cultures growing on glutamate, but in combination they caused a massive increase in the medium cyanide concentration. Cyanide production occurred near the end of exponential growth and during the early-stationary phase. Similar results have been obtained with $P$. deruginosa (Castric, 1975) and an unidentified pseudomonad (Wissing, 1968). Production of a compound during the transition period between the tropho- and idiophases of growth is typical of secondary metabolites (Drew \& Demain, 1977), suggesting that cyanide is such a product (Castric, 1975).

Cyanide production for growth of $C$. violaceum on $10 \mathrm{~mm}$-glutamate was optimal with 2 to 3 mm-glycine and 0.2 to 0.5 mM-methionine in the medium (not shown). These concentrations of glycine and methionine are lower than those previously reported for maximal cyanogenesis by $C$. violaceum (Michaels \& Corpe, 1965) and $P$. aeruginosa (Castric, 1977).

Cyanide production, and growth rate and final yield were relatively unaffected by growth in media with $\mathrm{pH}$ values in the range 6.0 to 8.0 . Although the growth rate was, as expected, 


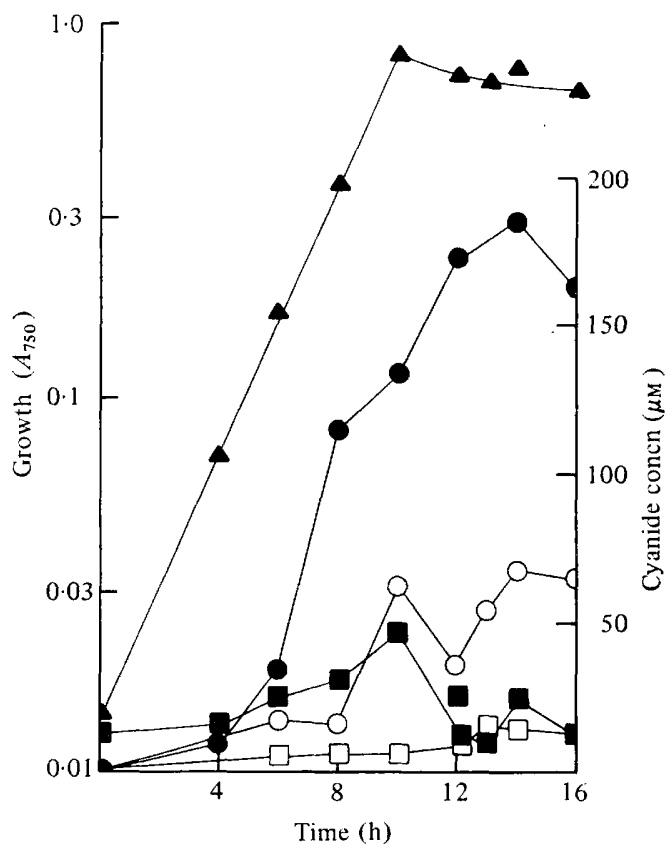

Fig. 1

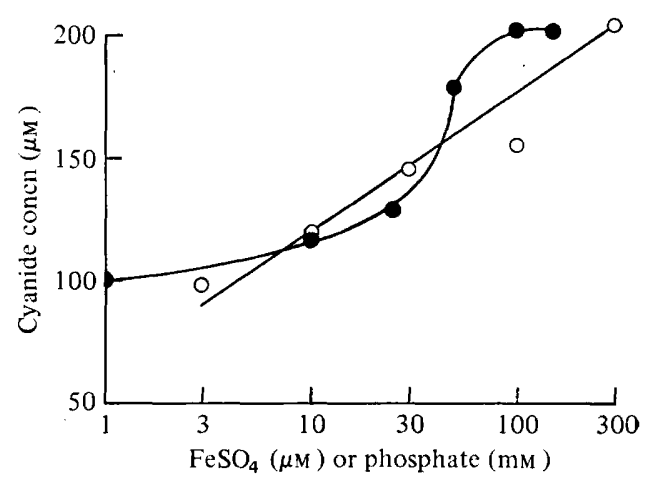

Fig. 2

Fig. 1. Growth and cyanide evolution by $C$. violaceum. For clarity, only growth in medium containing $10 \mathrm{~mm}$-glutamate is shown $(\mathbf{A})$. Cyanide evolution was followed during growth on $10 \mathrm{~mm}$ glutamate $(\square)$, and on $10 \mathrm{~mm}$-glutamate supplemented with $2 \mathrm{~mm}$-glycine ( $\mathbf{0}), 0.5 \mathrm{~mm}$-methionine $(\mathrm{O})$ and $2 \mathrm{~mm}$-glycine plus $0.5 \mathrm{~mm}$-methionine (O).

Fig. 2. Effect of ferrous ion (as $\mathrm{FeSO}_{4}$ ) concentration $(O)$ and phosphate concentration (O) on the maximum level of cyanide evolved by cultures of $C$. violaceum growing on $10 \mathrm{~mm}$-glutamate supplemented with 2 mM-glycine and $0.5 \mathrm{~mm}$-methionine. In the experiment where $\mathrm{FeSO}_{4}$ concentration was varied the phosphate content was maintained at $68 \mathrm{~mm}$, and where the phosphate content was varied the $\mathrm{FeSO}_{4}$ concentration was $30 \mu \mathrm{M}$.

affected by variation of the growth temperature in the range 25 to $35^{\circ} \mathrm{C}$, growth yield and cyanide production were essentially unaffected by the growth temperature.

Like $P$. deruginosa (Castric, 1975), cyanogenesis by $C$. violaceum was affected by the $\mathrm{Fe}^{2+}$ concentration of the medium (Fig. 2). Although higher concentrations of $\mathrm{Fe}^{2+}$ gave greater yields of cyanide, we have routinely used $30 \mu \mathrm{M}-\mathrm{FeSO}_{4}$ in growth media as higher levels caused precipitation. Increasing the medium phosphate concentration also caused an increase in cyanogenesis (Fig. 2). Above $100 \mathrm{~mm}$-phosphate the growth yield declined somewhat, and we have routinely used $68 \mathrm{~mm}$-phosphate in the medium. Chromobacterium violaceum appears to be different from $P$. deruginosa in its response to phosphate as Meganathan \& Castric (1977) have reported that cyanogenesis is inhibited in the latter organism by phosphate concentrations greater than $10 \mathrm{~mm}$.

Figure 3 shows the induction of $\beta$-cyanoalanine synthase $(a, b), \gamma$-cyano- $\alpha$-aminobutyric acid synthase $(c, d)$ and rhodanese $(e, f)$ during the late-exponential and early-stationary phases of growth of $C$. violaceum on glutamate $(a, c, e)$ or glutamate plus glycine and methionine $(b, d, f)$. In each case, the enzyme activity increased after about $8 \mathrm{~h}$ growth and reached a maximal value about $2 \mathrm{~h}$ after the stationary phase had been attained $(12 \mathrm{~h}$ growth). Inclusion of glycine plus methionine in the medium caused a significant reduction in the induction of $\beta$-cyanoalanine synthase and $\gamma$-cyano- $\alpha$-aminobutyric acid synthase, but not rhodanese, during the exponential-stationary phase (trophophase-idiophase) 


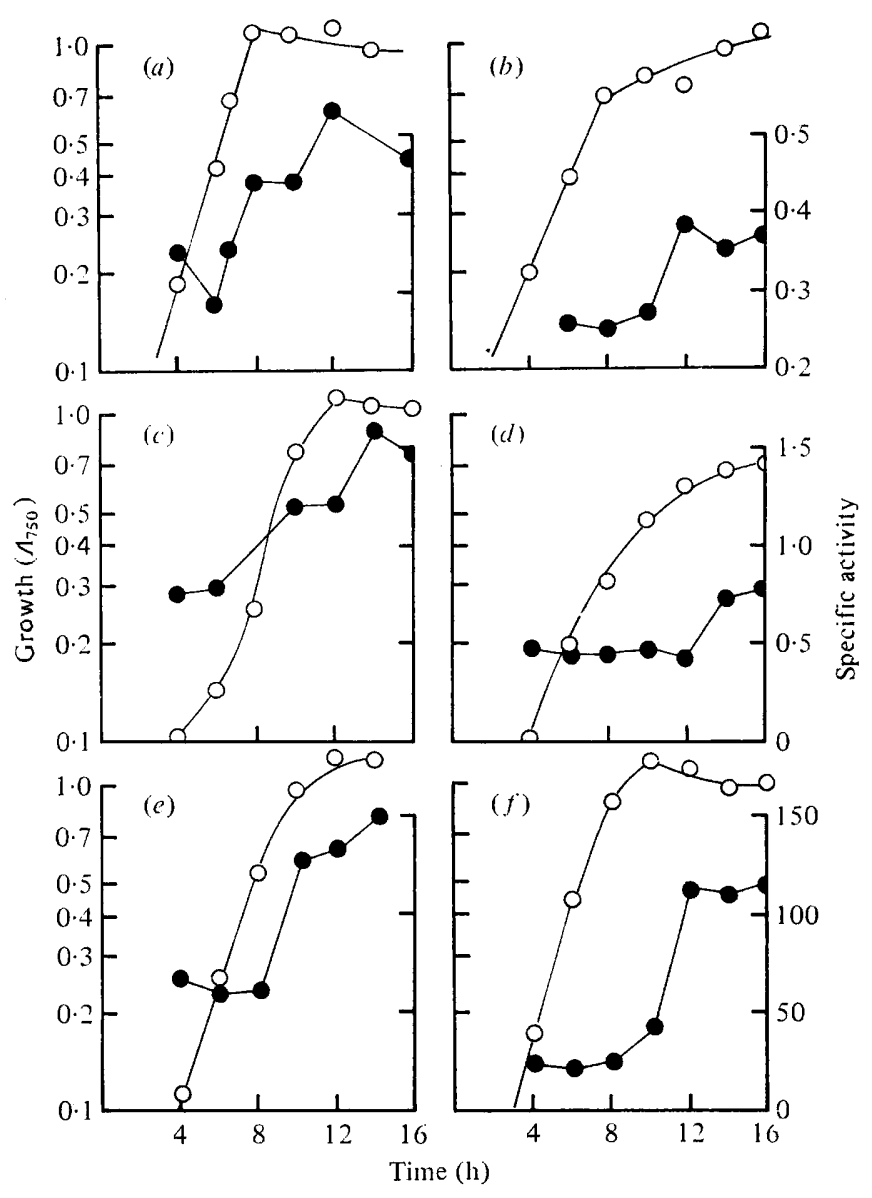

Fig. 3. Growth $(O)$ and specific activities of the cyanide-utilizing enzymes $(\bullet)$ in $C$. violaceum. $\beta$-Cyanoalanine synthase $(a, b), \gamma$-cyano- $\alpha$-aminobutyric acid synthase $(c, d)$ and rhodanese $(e, f)$ specific activities were assayed in cell-free extracts of cultures grown on $10 \mathrm{~mm}$-glutamate $(a, c, e)$ and on $10 \mathrm{~mm}$-glutamate supplemented with $2 \mathrm{~mm}$ glycine and $0.5 \mathrm{~mm}$-methionine $(b, d, f)$. Specific activity units: $\beta$-cyanoalanine synthase, $\mathrm{nmol}_{2} \mathrm{~S}$ evolved $\min ^{-1}$ (mg protein) ${ }^{-1} ; \gamma$-cyano$\alpha$-aminobutyric acid synthase, $\mathrm{nmol} \mathrm{SCN}^{-}$produced $\min ^{-1}$ (mg protein) ${ }^{-1}$; rhodanese, nmol dichlorophenolindophenol reduced $\min ^{-1}$ (mg protein $)^{-1}$.

transition period. Inclusion of glycine alone was also found to cause a reduction in the degree of induction of $\beta$-cyanoalanine synthase and $\gamma$-cyano- $\alpha$-aminobutyric acid synthase (not shown).

Following induction of these enzymes, the medium cyanide concentration decreased rapidly for cells induced for cyanogenesis (Figs 4 and $5 b$ ), presumably due to cyanide assimilation or detoxication especially via $\beta$-cyanoalanine synthase (Brysk et al., $1969 a$; Brysk et al., 1969b).

Addition of chloramphenicol to the medium in the exponential phase of growth prior to the onset of cyanide production $(5.5 \mathrm{~h}$ growth) caused an immediate cessation of growth and a dramatic reduction of cyanogenesis for cells growing with glycine and methionine in the medium (Fig. 4). Addition of chloramphenicol after $5.5 \mathrm{~h}$ growth on glutamate alone terminated growth but had no effect on the low level of cyanide produced (not shown).

For cells growing on glutamate alone, chloramphenicol added after $9.5 \mathrm{~h}$ growth caused a doubling of the medium cyanide content (Fig. $5 a$ ). When chloramphenicol was added 




Fig. 4. Effect of addition of chloramphenicol during the exponential phase on growth and cyanide evolution of $C$. violaceum growing on $10 \mathrm{~mm}$-glutamate supplemented with $2 \mathrm{~mm}$-glycine and $0.5 \mathrm{~mm}$-methionine. Chloramphenicol $\left(50 \mu \mathrm{g} \mathrm{ml}^{-1}\right)$ was added after $5.5 \mathrm{~h}$ growth (arrowed). Growth in the absence $(O)$ and presence $(O)$ of chloramphenicol and cyanide evolution in the absence $(\Delta)$ and presence $(\boldsymbol{\Delta})$ of cbloramphenicol were followed.

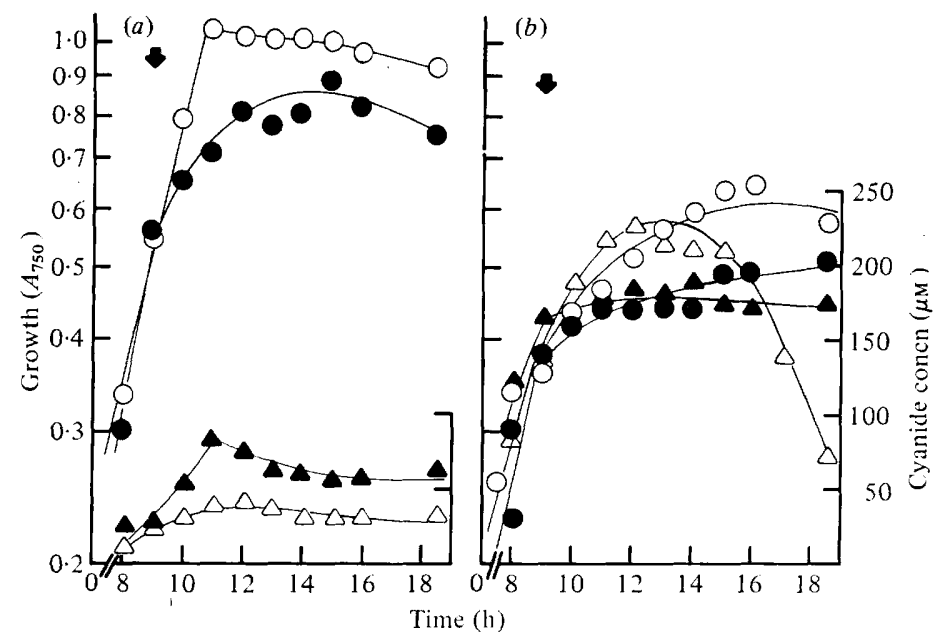

Fig. 5. Effect of addition of chloramphenicol during the late-exponential phase on growth and cyanide evolution of $C$. violaceum growing on $10 \mathrm{~mm}$-glutamate $(a)$ and on $10 \mathrm{~mm}$-glutamate supplemented with $2 \mathrm{mM}$-glycine and $0.5 \mathrm{mM}$-methionine $(b)$. Chloramphenicol $\left(50 \mu \mathrm{g} \mathrm{ml}^{-1}\right)$ was added to both cultures after $9.5 \mathrm{~h}$ growth (arrowed). Growth in the absence $(O)$ and presence $(O)$ of chloramphenicol and cyanide evolution in the absence $(\Delta)$ and presence $(\boldsymbol{\Delta})$ of chloramphenicol were followed in both cultures.

after cyanogenesis had commenced during growth on glutamate plus glycine and methionine $(9.5 \mathrm{~h}$ growth), the rate of decrease of medium cyanide content due to assimilation or detoxication decreased dramatically (Fig. $5 b$ ). In both cases, addition of chloramphenicol prevented induction of the enzymes for cyanide assimilation or detoxication (Table 1). If chloramphenicol was added at a time later than $9.5 \mathrm{~h}$ growth, the medium cyanide content was not affected showing that chloramphenicol did not inhibit the cyanideutilizing enzymes. 


\section{Table 1. Effect of addition of chloramphenicol to late-exponential phase cultures of C. violaceum on the induction of the cyanide-utilizing enzymes}

Chloramphenicol was added to a final concentration of $50 \mu \mathrm{g} \mathrm{ml}^{-1}$ after $9.5 \mathrm{~h}$ growth. The percentage increase in specific activity refers to the difference between activities measured at $8 \mathrm{~h}$ and at $12 \mathrm{~h}$ growth (see Fig. 3).

\begin{tabular}{|c|c|c|c|c|}
\hline \multicolumn{2}{|l|}{  } & \multicolumn{3}{|c|}{ Percentage increase in specific activity } \\
\hline Medium & Chloramphenicol & $\begin{array}{l}\beta \text {-Cyanoalanine } \\
\text { synthase }\end{array}$ & $\begin{array}{c}\gamma \text {-Cyano- } \alpha \text {-amino- } \\
\text { butyric acid } \\
\text { synthase }\end{array}$ & Rhodanese \\
\hline 10 mM-Glutamate & $\overline{+}$ & $\begin{array}{r}124 \\
28\end{array}$ & $\begin{array}{r}116 \\
0\end{array}$ & $\begin{array}{r}120 \\
15\end{array}$ \\
\hline $\left.\begin{array}{l}10 \mathrm{~mm} \text {-Glutamate }+ \\
2 \mathrm{~mm} \text {-glycine }+ \\
0.5 \mathrm{~mm} \text {-methionine }\end{array}\right\}$ & + & 52 & 58 & 340 \\
\hline
\end{tabular}

\section{DISCUSSION}

Wissing (1975) has recently obtained a bacterial cell-free extract capable of producing cyanide from glycine, but so far nothing is known about the enzymic step(s) involved in the conversion, although speculative pathways have been proposed (Knowles, 1976). On the other hand, several enzymes involved in cyanide assimilation and detoxication by cyanogenic micro-organisms have been identified, yet little is known about their properties and whether, for example, their activities are regulated by the cellular or medium cyanide, glycine or methionine levels (Knowles, 1976). Thus it is not possible to quantify the levels of the enzyme(s) involved in cyanide production during growth of $C$. violaceum and, whereas the activities of the assimilatory or detoxifying enzymes can be assayed in vitro, their activities in vivo cannot be estimated. Nonetheless, from measurements of the medium cyanide concentration, an assessment can be made concerning the balance between cyanide production and degradation in growing cultures of $C$. violaceum.

Experiments involving addition of glycine and methionine to cultures of $C$. violaceum several hours before measuring the ability to form cyanide from glycine have shown that glycine and methionine act as inducers of cyanogenesis (Michaels \& Corpe, 1965; Michaels et al., 1965), in addition to glycine being a precursor of cyanide. We have found that when chloramphenicol is added before the onset of cyanogenesis, to cultures growing in the presence of glycine and methionine, cyanide production is inhibited. This observation confirms that glycine and methionine at concentrations greater than the intracellular pool levels act as inducers of cyanide production, and shows that induction of the cyanideproducing enzyme(s) occurs in the late-exponential phase of growth. Furthermore, if chloramphenicol is added later, when maximal cyanogenesis is occurring, the level of cyanide production is only slightly affected but the following decrease in its concentration in the culture is inhibited. This indicates that the enzymes for cyanide assimilation or detoxication are induced only after cyanide production has occurred. In agreement with this supposition, assays of $\beta$-cyanoalanine synthase, $\gamma$-cyano- $\alpha$-aminobutyric acid synthase and rhodanese show that they increase in concentration at the start of the stationary phase, after cyanogenesis has occurred. It is possible that either cyanide or glycine acts as an inducer for the synthesis of these enzymes. However, addition of glycine alone to the medium, even though it does not cause induction of cyanogenesis, actually causes a small degree of inhibition of synthesis of the cyanide assimilating or detoxifying enzymes. It is therefore more likely that cyanide itself is an inducer of these enzymes. When growing on glutamate alone, where relatively little cyanide is produced, the assimilatory and detoxifying enzymes are induced in the stationary phase; possibly the low levels of cyanide formed under these conditions are still sufficient to act as inducers for the enzymes. Alternatively, the intra- 
cellular glycine or methionine pools could be sufficient to cause induction of the enzymes, especially if the pool sizes increase at the end of the exponential growth phase as the demand for glycine and/or methionine for other purposes decreases (see Drew \& Demain, 1977).

The low concentrations of cyanide found in the medium of cultures grown on glutamate in the absence of glycine and methionine is presumably due to the relatively lower rate of its production by the uninduced levels of the cyanide-forming enzyme system in comparison with its rate of removal by the degrading enzymes. Prevention of induction of the latter enzymes might be expected to result in an increase in cyanide concentration in the medium, as is observed (Fig. 5a).

The medium cyanide concentration will also depend on factors affecting the activities of the cyanide-degrading enzymes. Preliminary studies on the enzymology of these enzymes have shown that $\beta$-cyanoalanine synthase activity is about $60 \%$ inhibited by $2.0 \mathrm{~mm}$ methionine, yet higher concentrations of methionine cause little further inhibition. Glycine, although it repressed induction of this enzyme in the stationary phase (Table 1), has no effect on its activity. The activities of rhodanese and $\gamma$-cyano- $\alpha$-aminobutyric acid synthase were unaffected by glycine or methionine (P. B. Rodgers, unpublished observations).

This work was supported by the Science Research Council via grant no. GR/A/11543 to C.J.K. and a research studentship to P.B.R. Mrs P. A. Collins provided excellent technical assistance. We thank Dr L. F. Wright for helpful discussions.

\section{REFERENCES}

BAuchop, T. \& ElsDEN, S. R. (1960). The growth of micro-organisms in relation to their energy supply. Journal of General Microbiology 23, 457469.

BRYSK, M. M. \& RESSLER, C. (1970). $\gamma$-Cyano- $\alpha-L-$ aminobutyric acid. A new product of cyanide fixation in Chromobacterium violaceum. Journal of Biological Chemistry 245, 1156-1160.

Brysk, M. M., Corpe, W. A. \& Hankes, L. V. (1969a). $\beta$-Cyanoalanine formation by Chromobacterium violaceum. Journal of Bacteriology 97, 322-327.

Brysk, M. M., LAUINGer, C. \& Ressler, C. (1969b). Biosynthesis of cyanide from $\left(2{ }^{14} \mathrm{C}^{15} \mathrm{~N}\right)$ glycine in Chromobacterium violaceum. Biochimica et biophysica acta 184, 583-588.

CASTRIC, P. A. (1975). Hydrogen cyanide, a secondary metabolite of Pseudomonas aeruginosa. Canadian Journal of Microbiology 21, 613-618.

Castric, P. A. (1977). Glycine metabolism by Pseudomonas aeruginosa: hydrogen cyanide biosynthesis. Journal of Bacteriology 130, 826831.

Drew, S. W. \& Demain, A. L. (1977). Effect of primary metabolites on secondary metabolism. Annual Review of Microbiology 31, 343-356.

EPSTEIN, J. (1947). Estimations of microquantities of cyanide. Analytical Chemistry 19, 272-274.

Gornall, A. G., Bardawill, C. J. \& David, M. M. (1949). Determination of serum proteins by the biuret reaction. Journal of Biological Chemistry 177, 751-766.

Hendrickson, H. R. \& Conn, E. E. (1969). Cyanide metabolism in higher plants. Journal of Biological Chemistry 244, 2632-2640.
KNowLES, C. J. (1976). Microorganisms and cyanide. Bacteriological Reviews 40,652-680.

Meganathan, R. \& CASTRIC, P. A. (1977). The effect of inorganic phosphate on cyanogenesis by Pseudomonas aeruginosa. Archives of Microbiology 114, 51-54.

MiCHAELS, R. \& CORPE, W. A. (1965). Cyanide formation by Chromobacterium violaceum. Journal of Bacteriology 89, 106-112.

Michaels, R., Hankes, L. V. \& Corpe, W. A. (1965). Cyanide formation by non-proliferating cells of Chromobacterium violaceum. Archives of Biochemistry and Biophysics 11, 121-125.

MILLER, J. H. (1972). Experiments in Molecular Genetics, p. 431. Cold Spring Harbor, New York: Cold Spring Harbor Laboratory.

Ressler, C., Abe, O., Kondo, Y. \& Cottrell, B. (1973). Purification and characterisation from Chromobacterium violaceum of an enzyme catalysing the synthesis of $\gamma$-cyano- $\alpha$-aminobutyric acid and thiocyanate. Biochemistry 12, 5369-5377.

SMrTH, A. J. \& LASCELles, J. (1966). Thiosulphate metabolism and rhodanese in Chromatium sp. strain D. Journal of General Microbiology 42, 357-370.

WARD, E. W. B. \& THORN, G. D. (1966). Evidence for the formation of $\mathrm{HCN}$ from glycine by a snow mold fungus. Canadian Journal of Botany 44, 95104.

Wissing, F. (1968). Growth curves and pH-optima for cyanide producing bacteria. Physiologica plantarum 21, 589-593.

Wissing, F. (1975). Cyanide production from glycine by a homogenate from a Pseudomonas species. Journal of Bacteriology 121, 695-699. 